\title{
Prevalence of Cysticercosis Bovis in Eastern Shoa of Oromia, Ethiopia
}

\author{
Abdela Edao Lemi Korso
}

\begin{abstract}
Bovine cysticercosis is an infection of cattle caused by the larval stage, Cysticercus bovis of the human intestinal cestode, Taenia saginata. It is an infection of public health significance as eating of raw or undercooked beef results in taeniasis in human population and an important cause of economic loss mainly due to condemnation and downgrading of infected carcasses. A cross sectional study was conducted during April 2016 to August 2016 to estimate the prevalence of bovine cysticercosis in cattle slaughtered at Meki municipal abattoir. Routine inspection of carcasses and viability test were amongst the methods employed during data collection. Post mortem examination of 876 slaughtered cattle showed that $269(30.7 \%)$ were infected with $T$. saginata. Out of the total 447 cysts detected, 216(48.3\%) were found to be viable, while 231(51.7\%) were died cysts. The tongue, lung, masseter muscles, heart and triceps muscles were the main predilection sites of the cysts. Anatomical distribution based analysis of the cyst showed that highest proportions were observed in tongueas $(15.5 \%)$ followed by lung (14.4\%), masseter muscle 90(10.3\%), heart 61(6.9\%) and triceps muscle 34(3.9\%). Out of the 785 male cattle examined, 237 (30.2\%) had cysts of bovine cysticercosis while $32(35.2 \%)$ of the 91 female were infected. The prevalence varied significantly $(\mathrm{P}<0.05)$ between age groups, origin of animals and body condition score of animals, but no significant variation between sex of the animals. With respect to viable cysts, it was revealed that lung $(51.1 \%)$, tongue $(48.9 \%)$, heart $(28.6 \%)$, masseter muscle $(19.5 \%)$ and triceps muscle $(14.3 \%)$ were infected in decreasing order. The current study suggests that high prevalence of $T$. saginata metacestodes were observed in the source of animals and therefore sufficient emphasis should be given to this problem so as to improve health, quality and quantity of bovine that may satisfy the domestic requirements of the area and the country as general.
\end{abstract}

Keywords: Bovine, cysticercosis bovis, prevalence, Meki abattoir, Ethiopia

DOI: $10.7176 / \mathrm{JBAH} / 9-7-09$

Publication date: April $30^{\text {th }} 2019$

\section{Introduction}

In Ethiopia, meat inspection was started in 1910's with the aim of improving productivity and trade of livestock and their products as well as protecting the public from zoonotic diseases. Meat inspection as part of the veterinary public health activities ensures the delivery of hygienically processed meat for public consumption while preventing the transmission of infectious and zoonotic diseases to humans (Fufa et al., 2010; Fufa et al., 2011; Malaku et al., 2012). The activity also provides vital data and valuable information on the incidences and prevalence of animal diseases and conditions within any country (Ansari-Lari and Moazzeni, 2006; Phiri, 2006, Jibat et al., 2008; Yifat et al., 2011). The disease causes extensive financial wastes as a result of direct and indirect economic losses, is the major concern to the livestock industry.

Bovine cysticercosis is a parasitic zoonoses, which is caused by the zoonotic tapeworm Taenia saginata (Oladele, 2004). The occurrence of the larvae (cysticercus bovis) in cattle musculature causes bovine cysticercosis while the adult worms in human small intestine cause taeniasis (Neva and Brown, 1994; WHO, 1996; Minozzo et al., 2002). The life cycle of the parasite involves humans and cattles as final and intermediate hosts, respectively (Brown et al., 2012). An infected animal releases gravid segments that are shed by the adult fall to the ground and release eggs on the ground. Animals acquire infection from ingestion of segments and eggs contaminating herbage through faeces while grazing. Most incidents in cattle arise as a result of direct exposure to proglottids shed from farm workers, but there have been some reports of large scale outbreaks resulting from sewage contaminated feed or forage (Flutsch et al., 2008). The clinical effect of cysticercosis on infected animals is generally not significant, but it is economically important as it causes carcass condemnation as well as the cost of inspecting meat, the necessity to freeze or boil infected meat and losses may also occur from the restriction of live animal and animal products (Soulsby, 1982).

Globally, there are 77 million human carriers of the T. saginata out of which about $40 \%$ live in Africa. The average annual loss due to taeniacidal drugs for treatment in Ethiopia was estimated to be 4,937,583.21 Ethiopian birr (Ahmed, 1990; Dawit, 2004; Fufa, 2006).

In Ethiopia, cysticercosis was identified as a major health problem and production losses in domestic ruminants. Several studies have been conducted on the epidemiological distribution of bovine cysticercosis in different parts of Ethiopia (Megersa, 2010; Abunna, 2011; Fekadu, 2012). It has a worldwide distribution and the prevalence of cysticercus bovis is low in developed countries, being less than $1 \%$ in carcasses by inspection (Lumumba et al., 1996) and very common in Africa reaching a level of 30-36\% in Kenya, 20\% in Guinea, 18\% 
in Sierra Leone and 20\% in Cameroon (Gebreab, 1995). In African continent an annual loss was reported to be 1.8 billion USD under an overall infestation rate of 7\%. In South America, where an overall infestation rate was estimated at 2\%, caused an annual loss of 428 million USD (Mann, 1983; Fan, 1997). It is more important with regard to high economic losses due to the condemnation of heavily infected carcasses. Even though various investigations have been conducted through abattoir survey to determine the prevalence and economic losses resulting from organs condemnation in Ethiopia. Most of the survey focused on parasitic case such as hydatidosis, fasciolosis and cysticercosis (Jembere, 2002; Aseffa, 2005; Tolosa et al, 2009; Gomol, 2010; Zilalu, 2010; Kassa, 2012). In foreign trade, although the country is ideally placed to export live animals to the big markets of middle east and substantial markets of north and west Africa, export earnings is relatively low. This is mainly due to the presence of a number of unemployed animal health problems, among which, cysticercus bovis is one that remains a major public and animal health problem (EARO, 2000). The number of abattoirs increase in demand of the carcass and organ supply, but the supply is decreasing due to disease, production and other various constraints. In view of this, the current status of organ condemnation and the evaluation of the prevalence of cysticercosis from various abattoirs including Meki municipal abattoirs are needed.

Based on abattoir survey, the prevalence reports of bovine cysticercosis in Ethiopia showed variable results with localities. Relatively lower prevalence was reported 2.59\% in Wolaita Soddo (Dawit et al., 2012), 3.1\% in central Ethiopia (Tembo, 2001), 4.9\% in Gondar (Dawit, 2004) and 7.5\% in Addis Ababa (Nigatu, 2004) were reported, while higher prevalence of $17.5 \%$ in East Shoa (Hailu, 2005), 21\% in Nekemte (Ahmed, 1990), and Hawassa (22.9\%) (Mesfin and Nuraddin, 2012) and (26.25\%) (Abunna et al., 2007).

In Oromia, particularly in the East Shoa zone, livestock raising is an important activity from which food and non-food commodities are produced. Among the prevalent livestock diseases; zoonotic represents major constraints to the development of livestock productivity in the country. Among zoonotic diseases, bovine cysticercosis is the disease that remains a major public health problem in lower income and some industrialized countries (Utulas et al., 2007). It is, therefore, important that due attention be given to this disease to improve the quality and quantity of meat cattle so as to satisfy the domestic consumption. But the productivity remains very low due to lack of disease control, farmers and butchers in Meki area pay very little attention to this disease and poor husbandry practice. And previously there were no any data on the study area to determine the prevalence of the disease and its rate in different organs. Hence, the objective of this paper was to determine the prevalence of cysticercus bovis of cattle slaughter at Meki municipality abattoir.

\section{Materials and Methods \\ Study area}

The study was conducted in Meki, East Shoa Zone of Dugda district, at Meki municipal abattoir in Oromia regional state, located in the central Rift Valley of Ethiopia. Meki is the capital of Dugda district, located at $8^{\circ} 01^{\prime} \mathrm{N}$ latitude and $38^{\circ} 31^{\prime} \mathrm{E}$ longitude. It has $95,945 \mathrm{~km}^{2}$ of land inhabited by about 157818 people of which more than $85 \%$ are living in the rural areas. The town is $134 \mathrm{~km}$ far away from capital Addis Ababa and $86 \mathrm{~km}$ from Adama, head town of East Shoa Zone with an altitude ranging between 1600 and 2020 masl and average annual rainfall ranges from $650-750 \mathrm{~mm}$ and the distribution is highly variable between and within years. Agro ecologically, the area is categorized under the semi-arid, with minimum mean temperature of $22^{\circ} \mathrm{C}$ and maximum mean temperature of $28^{\circ} \mathrm{C}$ with relative humidity of $60 \%$. Vertisol is the predominant soil type with sandy-loam-clay in the portion of 33:48:18; respectively and has a $\mathrm{pH}$ of 7.88 . Crop-livestock mixed farming system characterizes agriculture in the district. Livestock production continues to be the major economic activity and is still the status symbol for farmers in Dugda district. Cattle, sheep, goats, equines and chickens are important livestock species reared. Maize, haricot bean, teff, wheat barley, cereals and pulses and sorghum are grown under rain fed condition by peasant farmers (DWADB, 2016). Livestock population of the district has a total head of 228686 of cattle, 70263 of sheep, 62705 of goats, 20017 of donkeys, 5193 of horses, 2166 of mules and 183665 of poultry (DWLDH, 2016).

\section{Study design}

A cross-sectional study was conducted on cysticercus bovis from April 2016 to August 2016 at the Meki municipal abattoir. The explanatory variables considered were age, sex, body condition and source location of the host as related factors.

\section{Sample size determination}

The required sample size for the study was determined with 5\% desired level of precision and $95 \%$ confidence interval. Since there was no record of previous prevalence assumption of $50 \%$ expected prevalence of cysticercus bovis in slaughtered cattle was taken in the study area. By substituting the value in the below formula by (Thrusfield, 2005); the minimum sample size of 384 animals was considered. 


$$
n=\frac{(1.96)^{2} P \exp (1-P \exp )}{d^{2}}
$$

Where; (n) is required sample size, (Pexp) is expected prevalence,

(d) is desired absolute precision.

By using the above formula, the required sample size was calculated to be 384 . But to increase Precision, 492 animals were added and a total of 876 cattle destined for slaughter were taken as and inspected. Every animal during the study period was examined after and before slaughter and data was recorded.

\section{Sampling methods}

Ante mortem inspection (AMI): Pre-slaughter examination of cattle will be conducted in the lairage by grouping the animals based on species, sex, age, body condition score and place of origin. The age grouping will be based on dentition. Those which have not erupted permanent incisor teeth will be classified as young, while those with one pair or more permanent incisor teeth will be classified as adults (Vatta et al., 2006). Ante mortem inspection was conducted on individual animals, while the animals were entered into the lairage in mass. Both sides of the animals will be inspected at rest and in motion. Moreover; the general behavior of the animals, gait, structure, body condition scoring and signs of disease and abnormalities of any type were registered according to the standard of ante mortem examination procedures given by Gracey (1986). Following these, judgments were passed based on FAO (2004).

Post mortem examination (PME): Animals that undergo post mortem examination will be those which passed ante mortem inspection. During postmortem inspection liver, lungs, heart, kidney, tongue, brain, muscles and carcasses will be thoroughly inspected by visualization, palpation and making systemic incisions where necessary for the presence of cysts, parasites and other abnormalities.

\section{Data analysis}

The data recorded was entered into Microsoft excel and the statistical (SPSS) version 20 was used to analyze the data. The prevalence was calculated as the number of positive samples divided by the total number of examined samples. Chi-square $(\chi 2)$ test was used to assess the association between the prevalence of cysticercus bovis and host related risk factors such as sex, age, origin and body score of the animals. P-value $<0.05$ was considered as significant.

\section{Results}

The overall prevalence of cysticercosis bovis on the inspected bovine in the present study was $30.7 \%$ $(269 / 876)$. There was a statistical difference $(\mathrm{P}<0.05)$ between body condition and origin of animals with the prevalence of infection, but there was no statistical difference $(\mathrm{P}>0.05)$ between age and sex groups of animals.

\section{Occurrence of cysticercus bovis in different organs of bovine}

Masseter muscles, tongue, triceps muscles, lungs and heart are the organs that were inspected for the presence or absence of cysticercus bovis. The abattoir survey analysis clearly indicated that there was a significant variation with regard to degree of infestation in the inspected organs of slaughtered animals. Cysticercosis bovis was found with higher number of cysts encountered in the tongue $15.5 \%$, followed by lungs, masseter muscles, heart and triceps muscles (Table 1).

Table 1. The overall prevalence of cysticercosis bovis infection in different organs of the cattle examined $(\mathrm{n}=$ 876), Meki abattoir, Ethiopia.

\begin{tabular}{lll}
\hline Organs inspected & Number of positive & Prevalence \% \\
\hline Tongue & 136 & 15.5 \\
Lungs & 126 & 14.4 \\
Masseter muscles & 90 & 10.3 \\
Heart & 61 & 6.9 \\
Triceps muscles & 34 & 3.9 \\
\hline Total & 447 & 61.6 \\
\hline \multicolumn{2}{c}{ Regarding to origin of animals, the highest prevalence was observed in cattle from Habura (53.3\%) } \\
followed by Batu, Alemtena, Arsinagele and the least compared to other was from Meki (Table 2).
\end{tabular}


Table 2: The overall prevalence of bovine cysticercosis infection based on the basis of age, sex, origin place and body condition scores of the cattle examined $(n=876)$, Meki abattoir, Ethiopia.

\begin{tabular}{|c|c|c|c|c|c|}
\hline Risk factors & & $\begin{array}{l}\text { No. } \\
\text { inspected }\end{array}$ & No. infected & Prevalence \% & $\mathrm{X}^{2}$ (P-value) \\
\hline \multirow[t]{6}{*}{ Age } & Young & 292 & 105 & 36 & \\
\hline & Adult & 584 & 164 & 28.1 & $5.676(0.017)$ \\
\hline & Total & 876 & 269 & 30.7 & \\
\hline & Meki & 632 & 167 & 26.4 & \\
\hline & Arsi Nagele & & & & \\
\hline & & 86 & 32 & 37.2 & \\
\hline \multirow{4}{*}{$\begin{array}{l}\text { Origin of } \\
\text { Animals }\end{array}$} & Batu & 63 & 27 & 42.9 & $23.605(0.000)$ \\
\hline & Alemtena & 50 & 19 & 38 & \\
\hline & Habura & 45 & 24 & 53.3 & \\
\hline & Total & 876 & 269 & 30.7 & \\
\hline \multirow{4}{*}{$\begin{array}{l}\text { Body } \\
\text { condition } \\
\text { score }\end{array}$} & Medium & 103 & 59 & 57.3 & \\
\hline & Good & 773 & 210 & 27.2 & $38.738(0.000)$ \\
\hline & Total & 876 & 269 & 30.7 & \\
\hline & Male & 785 & 237 & 30.2 & \\
\hline \multirow[t]{2}{*}{ Sex } & Female & 91 & 32 & 35.2 & $0.948(0.330)$ \\
\hline & Total & 876 & 269 & 30.7 & \\
\hline
\end{tabular}

A total of $447(61.6 \%)$ cysts were recovered from 269 cysticercosis positive animals during the study period. Out of the total of 447 cysts detected, $48.3 \%$ were found to be viable, while $51.7 \%$ were died cysts (Table 3 ).

Table 3: Frequency of cysticercus bovis in different organs and tissues of the cattle examined in Meki abattoir, Ethiopia.

\begin{tabular}{llll}
\hline Organs inspected & Viable cysts (\%) & Dead cysts $(\%)$ & Total cysts $(\%)$ \\
\hline Tongue & $65(48.9 \%)$ & $71(9.6 \%)$ & $136(15.5 \%)$ \\
Lungs & $68(51.1 \%)$ & $58(7.8 \%)$ & $126(14.4 \%)$ \\
Masseter muscles & $26(19.5 \%)$ & $64(8.6 \%)$ & $90(10.3 \%)$ \\
Heart & $38(28.6 \%)$ & $23(3.1 \%)$ & $61(7.0 \%)$ \\
Triceps muscles & $19(14.3 \%)$ & $15(2.0 \%)$ & $34(14.4 \%)$ \\
\hline Total & $216(48.3 \%)$ & $231(51.7 \%)$ & $447(61.6 \%)$ \\
\hline
\end{tabular}

\section{Discussion}

Taeniosis/cysticercosis occurs most commonly in the environments characterized by poor sanitation, primitive livestock husbandry practice and inadequate meat inspection and control. Bovine cysticercosis usually does not cause much morbidity or mortality among cattle, but it does cause serious economic problems in the endemic areas due to the condemnation of meat or downgrading of carcasses contributing to constraint in food security and safety (Lumumba et al., 1996; Kyule et al., 2003). The results of the present study also reflect both the economic and zoonotic importance of this disease, which is in agreement with the above statements. In the current study, the prevalence of bovine cysticercosis was $30.7 \%$, which was in line with the report of Abunna et al. (2007) in Hawassa abattoir (26.25\%) and Mesfin and Nuraddis (2012) who reported cysticercus bovis prevalence of $22.9 \%$. The current finding was relatively higher than previous findings of Addisu and Wondimu (2015) which implies prevalence of bovine cysticercosis was 2.6\% in and around Batu, Tembo (2001) in central Ethiopia (3.11\%), Nuraddis and Frew (2012) in Addis Ababa municipal abattoir (3.6\%), Dessie (1992) in Assela (2.7\%), Tolosa et al. (2009) and Gomol et al. (2011) in Jimma municipal abattoir with a prevalence of $2.93 \%$ and $3.6 \%$, respectively, of Dawit et al. (2012) in Wolaita Soddo (2.59\%) and of Teka (1997), in which the prevalence was $2.2 \%$.

Association of cysticercus bovis with potential risk factors revealed a significant relationship $(\mathrm{p}<0.05)$ with age being higher in young $(36 \%)$ as compared to that of old aged animals $(28.1 \%)$. This finding was in agreement with the reports of Hailu (2005), Tembo (2001) and Nuraddis and Frew (2012). However, it contradicts with the findings of Gomol et al. (2011), Jemal and Haileluel (2011), Dawit et al. (2011) and Mesfin and Nuradddis (2012). This significant variation might be due to age dependent immunity of an animal that had an important role to play in fighting against infestation and re-infestation of cysticercus bovis. The re-stimulation of animal's immunity following the continuous invasion of onchospheres would explain the development of a 
strong immunity, which did not allow further development of more cysticerci from invading onchospheres, but spared viable cysticerci from the initial infestation (Jemal and Haileleul, 2011; Nuraddis and Frew, 2012 ). In addition, this might be due to that any age groups of animal have a close susceptibility to $T$. saginata (Nuraddis and Frew, 2012).

There was no statistical difference $(\mathrm{P}>0.05)$ with sex associated with cysticercus bovis infection. This was in line with the report of Gomol et al. (2011), Jemal and Haileluel (2011), Dawit et al., (2012), Mesfin and Nuradddis (2012) and Haylegebriel and Alembrhan (2012). Nevertheless; this finding was in contrary to that of Nuraddis and Frew (2012) who reported that statistically significant difference was observed between sexes of slaughtered animals. The possible reason for the non-significant difference between male and female slaughtered animals might be due to the fact that most of the animals brought to the abattoir had similar husbandry systems (the same type of livestock management) and both sexes were equally exposed to the disease in all districts, which leads to equal exposure of animals to $T$. saginata eggs. Regarding the predilection sites of the cyst, the current finding revealed that the highest number of cysts was found on the tongue $(15.5 \%)$ followed by lungs $(14.4 \%)$, masseter muscles $(10.3 \%)$, heart $(6.9 \%)$ and triceps muscle $(3.9 \%)$. This finding was in agreement with the report of Ahmed (1990), Hailu (2005), Solomon (1994), Amsalu (1989), Abunna et al. (2007) and Mesfin and Nuradddis (2012) who reported that tongue was the most frequently affected organ and in contrary to this Dawit et al. (2012), Haylegebriel and Alemberhan (2012) and Nzeyiman et al. (2015) who reported that heart as being frequently affected by the cyst. Similarly, the current finding contradicts with the earlier finding of Minozzo et al. (2002) who reported that higher populations of cysts were found in the masseter muscles. However, this result was not in line with Gracey (1986), Getachew (1990), Tolosa et al. (2009), Gomol et al. (2011), Jemal and Haileleul (2011) and Nuraddis and Frew (2012) indicated that the triceps being the most frequently affected muscles by cysticercus bovis.

The variation between organs of the slaughtered animals might be due to blood kinetics and animals daily activities. Any geographical and environmental factors affecting the blood kinetics in the animal affect the distribution of onchospheres as well and hence the predilection sites varies during meat inspection. Most of these organs, except the heart are consumed raw or under cooked and could be a potential public health hazard in contracting taeniasis.

The above difference in prevalence of infection might be associated with many reasons, including time of occurrence (higher in dry season than rainy season) (Jemal and Haileleul, 2011; Nigatu, 2004), sample size, type of re-infection, status of the people in the environment, the practical limitation to the number of incisions allowed in skeletal muscles, limit to the number and intensity of the incisions made during meat inspection (as this will reduce market price of the carcass) and the knowledge and ability of researchers (Jemal and Haileleul, 2011). Differences in the skills and motivation of meat inspectors, the speed of slaughter activity and the meat inspection facilities are among the many other contributory factors. The observations showed that the lungs, tongue, masseter muscles, triceps muscle and heart among others were the preferred organs (predilection site) for the cysts of bovine cysticercosis similar to earlier reports in various endemic areas (Pawlowski and Schultz, 1972; Okafor, 1988; Moreira et al., 2001; Opara et al., 2006). It appears that several factors such as activity of the muscles, age and the geographical area concerned determine largely the predilection sites in slaughtered cattle (Petrovic, 1976; Minozzo et al., 2002; Opara et al., 2006).

\section{Conclusion}

Bovine cysticercosis is one of the major zoonotic diseases that remain a major health problem of animals and humans causing serious socio-economic impact. Since the prevalence found in the current study was relatively high (30.7\%), its significance on the health of both animals and public should not be underestimated. Therefore; special attention should be given so as to prevent and control the spread of this disease in animals and in humans.

\section{Acknowledgements}

The authors would like to acknowledge and appreciate the financial support of the sister Hiko Korso. Likewise, the Ethiopian Catholic Church Social Development Coordinating Office of Meki (ECC-SDCOM) is also acknowledged.

\section{References}

Abunna. A., Dasta. R., Alemayehu. M., Bekele.Fand Debela.E (2011). Major metacestodes in cattle slaughtered at Nekemte Municipal Abattoir, Western Ethiopia: Prevalence, Cyst Viability, Organ Distribution and Socio Economic Implications, Biomirror, 2 (10): 1-7.

Abunna. F., Tilahun.G.,Megersa, A.,Regassa.Fand Kumsa.B, (2007). Bovine cysticercosis in cattle slaughtered at Awassa municipal abattoir, Ethiopia: Prevalence, cyst viability, distribution and its public health implication. East African Journalon Public Health, 4(2): 73-79.

Addisu.D and Wondimu.D, (2015).Prevalence of Taeniasaginata/cysticercosis and community knowledge about 
zoonotic cestodes in and around Batu, Ethiopia.

Ahmed. I.(1990). Bovine cysticercosis in slaughtered at Nekemte abattoir. DVM Thesis, Addis Ababa University, Faculty of Veterinary Medicine, DebreZeit, Ethiopia.

Ansari-Lari.M. and Moazzeni M.(2006).A retrospective survey of liver fluke disease in livestock based on abattoir data in Shiraz, south of Iran. Preventive Veterinary Medicine, 73: 93-96.

Aseffa.M.(2005). Parasitic causes of carcass/organ condemnation at Asella municipality abattoir. DVM thesis, Addis Ababa University, Faculty of Veterinary Medicine, DebreZeit, Ethiopia.

Brown.W, Lees. J, Nightingale. B, Scandrett.Kand Gajadhar.A(2012). Outbreak of Cysticercosisbovis(T. saginata) in feedlot cattle in Alberta, Canada.Veterinary Journal, vol. 43, pp. 227-228.

Dawit.S.(2004).Epidemiology of Taeniasaginata(taeniasis) and cysticercosis in North Gondar Zone, NorthWestern Ethiopia.DVM Thesis; Addis AbabaUniversity, Faculty of Veterinary Medicine, DebreZeit, Ethiopia.

Dawit. T.,Tewodros. S. and Tilaye.D, (2012). Public Health and Economic Significance of BovineCysticercosisinWolaitaSoddo,Southern Ethiopia.Global Veterinaria, 9(5): 557-563, I D O S I P u b 1 i c a t i o n s. DO I: 10.5829/idosi.gv.2012.9.5.6547.

Dessie.S. (1992).Economic significance of bovine fasciolosis, hydatidosis and cysticercosis at Assela municipal abattoir.DVM Thesis, Addis Ababa University, Faculty of Veterinary Medicine, DebreZeit, Ethiopia.

DWADB (DugdaWoreda Agricultural Development Bureau).(2015). Annual report and result record.

DWLDHB (DugdaWoreda Livestock Development and Health Bureau). (2016). Annual report and result record.

EARO (EthiopianAgricultural Research Organization).(2000). Beef Research Strategy.Animal Science Directorate.

FAO (2004).(Food and Agriculture Organization) of the United Nations.

Fekadu. E., Legesse. Land Tesfaye.D(2012). The cause, rate and economic implication of organ condemnation of cattle slaughtered at Jimma Municipal Abattoir, Southwestern Ethiopia, Global Veterinaria, vol. 9, no. 4, pp. 396-400.

Flutsch. D, Heinzmann.A., Mathis. H, Hertzberg. R, Stephan.M andDeplazes .P(2008).Case-control study to identify risk factors for bovine cysticercosis on farms in Switzerland, Parasitology, vol. 135, no. 5, pp. 641646.

Fufa. A., Ayala.D,Regassa.A.,Megersa.B andEtana.D.(2011). Major Metacestodes in Cattle Slaughtered at Nekemte Municipal Abattoir, Western Ethiopia: Prevalence, Cyst Viability, Organ Distribution and Socioeconomic Implications. Biomirror, 2: 1-7.

Fufa. A.,Asefaw.L.,Megersa.B andRegassa.A.(2010). Bovine fasciolosis: coprological, abattoir survey and its economic impact due to liver condemnation at Sodo Municipal abattoir, Southern Ethiopia. Tropical Animal Health and Production, 42: 289-292.

Getachew.B. (1990). Prevalence and significance of Cysticercusbovis among cattle slaughtered at DebreZeit Abattoir. Addis Ababa University, Faculty of Veterinary Medicine, DebreZeit, Ethiopia.

Gomol.T.(2010). Cysticercusbovis: Prevalence and cyst viability at Jimma Municipal abattoir, south west of Ethiopia. DVM thesis, University of Gondar, Faculty of Veterinary Medicine, Gondar, Ethiopia.

Gomol.T.,Achnef.M., Basazenuw.B. andMersha.C.(2011).Cyst viability, Body site distribution and public health significance of bovinecysticercosis at Jimma, South west Ethiopia. IDOSI Publications, Global Veterinaria, 7(2): 164-168.

Gracey.J, Collins .D and Huey .R (1999)meat hygiene.

Gracey, J. and Collins.D.(1986). Meat hygiene.7 ed. Bailliere Tindal, London. 24-28 Oval Road, London NW17DX, pp: 413-420.

Gracey, J. and Collins.D(1992). Meat hygiene.9 ed. Bailliere Tindal, London. 24-28 Oval Road, London NW17DX.

Hailu, D. (2005). Prevalence and risk factors for Taeniasaginata,cysticercosis in three selected areas of eastern Shoa.MSc. Thesis Addis Ababa University, Faculty of Veterinary Medicine, DebreZeit, Ethiopia.

HaylegebrielTesfay and AlembrhanAssefa(2012). Cysticercosisbovis in Eastern Tigray, Northern Ethiopia. International Journal of Innovation and Scientific Research ISSN, pp: 2351-8014 Vol. 10 No. 2 Oct. 2014.

JemalEndris and HaileleulNegussie (2011). Bovine cysticercosis: Prevalence, Cyst viability and distribution in cattle slaughtered at KombolchaElfora meat factory, Ethiopia. American EurasianJournal of Agriculture and EnvironmentalSci., 11: 173-176.

Jembere, S. (2002).A study on causes of organ and carcass condemnation in slaughtered cattle at Nazareth abattoir.DVM thesis.Addis Ababa University, Faculty of Veterinary Medicine, DebreZeit, Ethiopia.

Jibat.T.,Ejeta.G., Asfaw.Y. andWudie.A.(2008).Causes of abattoir condemnation in apparently healthy slaughtered sheep and goats at Helmex abattoir, DebreZeit, Ethiopia.Revue de MedecineVeterinaire, 159: 305-311.

Kassa.S.A.(2012). Cystic hydatidosis in Ethiopia: a review on Scientific Journal of Crop Science, 1: 1-8. 
Megersa. E., Tesfaye. A., Regassa. R., Abebe.M and Abunna.F.( 2010) "Bovine cysticercosis in Cattle Slaughtered at Jimma Municipal Abattoir, South western Ethiopia: Prevalence, Cyst viability and Its Socioeconomic importance," VeterinaryWorld, vol, 3 no. 6 pp. 257-262,.

Melaku, A., Lukas.B. and Bogale .B.(2012). Cyst Viability, Organ Distribution and Financial Losses due to Hydatidosis in Cattle Slaughtered at Dessie Municipal Abattoir, North-eastern Ethiopia Veterinary World, 5: $213-218$.

Mesfin, B. and Nuradddis, (2012).Prevalence of Cysticercusbovis in Hawassa Municipal AbattoiranditsPublicHealthImplication.American-Eurasian Journal of Scientific Research, 7(6): 238-245, IDOSI Publications. DOI: 10.5829/idosi.aejsr.2012.7.6.6565.

Minozzo,J., Gusso,E., Castro Lago and V.T.Soccoi (2002).Experimental Bovine Infection with Taeniasaginata eggs. Recovery rate and cysticerci location.Braz.Arch.Biol.Technol., 45:451-455.

MOA (1972).Meat Inspection Regulations.Legal notice No. 428.NegariteGazexa, Addis Ababa, Ethiopia.

Moreira,M.,Reis.D.,Almeida.L and W.L.Santros(2001). Re-emerging zoonosis:Bovinecysticercosis in abattoirs in Uberlandia.Hygiene Alimentarius Brazil,15:16-19.

Neva. A. and Brown.W.(1994). Basic clinical parasitology. $6^{\text {ed }}$. Prentice-Hall International Inc., pp: 181-200.

Nigatu.K.(2004). Cysticercusbovis: Development and evaluation of serological tests and prevalence at Addis Ababa Abattoir. MSc.Thesis, Addis Ababa University, Faculty of Veterinary Medicine, DebreZeit, Ethiopia.

Nuraddis, I. and Frew.Z., (2012). Prevalence of TaeniaSaginataCysticercosis in Cattle Slaughtered in Addis Ababa Municipal Abattoir, Ethiopia.JimmaUniversity, School of Veterinary Medicine, Ethiopia. IDOSI Publications, Global Veterinaria, 8(5): 467-471, 2012.

Nzeyimana, P., Habarugira. J, Udahemuka. B, Mushongaand Tukei.M.(2015). Prevalence of bovine cysticercosis and age relationship at post-mortem in Nyagatare Slaughterhouse, Rwanda.World Journal of Agricultural SciencesVol. 3(1): 004-008, March 2015. Available online athttp://wsrjournals.org/journal/wjas.

Okafor.F.(1988).Epizootiologyof Cysticercusbovis in Imo state,Nigeria.Angew.Parasitol.,29:25-30.

Oladele.O.(2004), "Bovine cysticercosis: Preliminary observations on the immunohistochemical detection of $T$. saginataantigens in lymph nodes of an experimentally infected calf," Canada Veterniary Journal, vol. 45, pp. $852-855$.

Opara,M., Ukpong.U.,Okoli.I and Anosike.J(2006). Cysticercosis of slaughter cattle in Southeastern Nigeria.Animal Academic Science.1081: 339-346.

Pawlowski.Z.andSchultz.M.(1972).Taeniasis and cysticercosis (Taeniasaginata). Advanced Parasitology.,10: 269-343.

Petrovic.A.(1976).On the incidence of Cysticercusbovis in Tanzania.Vet.Glesnik,30:709-713.

Phiri, A. (2006). Common conditions leading to cattle carcass and offal condemnation at three abattoirs in western province of Zambia and their zoonotic implication to consumers.Journal of the South African Veterinary Association, 77: 28-32.

Soulsby (1982), Helminths, Arthropods and Protozoa of Domestic Animals, $7^{\text {th }}$ Edition, London, Bailliere Tindal,.

Teka.G.(1997). Food Hygiene Principles and Food Borne Disease Control with Special Reference toEthiopia. 1 ed Faculty of Medicine Department ofCommunity Health, Addis Ababa University.

Tembo. A.(2001).Epidemiology of Taeniasaginata, Taeniasis/ Cysticercosis in three selected agro-climatic zones.MSc.Thesis, Facultyof Veterinary Medicine, Free University of Berlin, Berlin, Germany.

Tolosa. T.,Tigre.W,Teka.G and Dorny.P.(2009). Prevalence of bovine cysticercosis and hydatidosis in Jimma municipal abattoir,South West Ethiopia.OnderstepoortJournal of Veterinary Research, 76: 323-326.

Utulas.M.,Esatgil and Tuzer, (2007). Prevalence of Hydatidosis in slaughtered animals in Thrace, Turkey. Parasitology Dergist, 31(1): 41-45.

Vatta, A.,Abbo.M.,Villiers.J,Gumeda.S,Harrison.L.,Krecek.R, Letty.B,Mapeyiand.N and Pearson.R.(2006). Goat keeper's animal healthcare manual. Agricultural Research council.OnderstepoortVeterinary Institute with KwaZulu-natal department of agriculture and environment, South Africa.

Wanzala.W.,Onyango.J.,Kang’ethe.E.,Zessis.K.,Kyule.N,Baumann.M, Ochanda.N and Harrison.L.(2003). Control of Taeniasaginatabypostmortem examination of carcasses.Aft. Health Sci., 3(2): 68-76.

WHO (1996). Investigating in Health Research and Development. Report of the committee on health research relating to future intervention options.Geneva, Switzerland: WHO, pp: 270-275.

Yifat. D.,Gedefaw.Dand Desie.S(2011). Major Causes of Organ Condemnation and Financial Significance of Cattle Slaughtered at Gondar Elfora Abattoir, Northern Ethiopia. Global Veterinaria, 7: 487-490.

Zilalu.S.(2010). Study on the prevalence of Cysticercusbovis in slaughtered animals in HashimNuru's export Abattoir, at Debrezeit. DVM thesis, University of Gondar, Faculty Veterinary Medicine, Gondar, Ethiopia. 